\title{
Prevalence and overlap of different lipid abnormalities in statin-treated patients at high cardiovascular risk in clinical practice in Germany
}

\author{
Anselm K. Gitt · Claus Jünger · Wenefrieda Smolka • \\ Kurt Bestehorn
}

Received: 19 October 2009/ Accepted: 18 May 2010/Published online: 3 June 2010

(C) The Author(s) 2010. This article is published with open access at Springerlink.com

\begin{abstract}
Background In line with current guideline recommendations, patients at high cardiovascular risk are usually treated with statins for secondary as well as for primary prevention. While many studies investigated treatment goal achievement with regards to low-density lipoprotein (LDL-C) and total cholesterol (TC) there is paucity of data regarding high density lipoprotein (HDL-C), and/or triglycerides (TG).

Setting Prospective, cross-sectional study (Dyslipidemia International Survey, DYSIS) with data provided by 748 office-based physicians throughout Germany.

Methods Consecutive patients were eligible for participation, if they were at least 45 years old, currently treated with a statin and had had a documented lipid profile
\end{abstract}

A. K. Gitt · C. Jünger

Institut für Herzinfarktforschung Ludwigshafen an der

Universität Heidelberg, Ludwigshafen, Germany

A. K. Gitt

Kardiologie, Medizinische Klinik B, Herzzentrum

Ludwigshafen, Ludwigshafen, Germany

W. Smolka $\cdot$ K. Bestehorn $(\bowtie)$

Medical Department, MSD Sharp \& Dohme GmbH,

85540 Haar, Germany

e-mail: kurt.bestehorn@msd.de

K. Bestehorn

Institute for Clinical Pharmacology, Technical University,

Dresden, Germany (at least 1 parameter) within the last 6 months. Besides descriptive analyses, logistic regression was performed with backward selection to assess predictors for lipid abnormalities (non-attainment of goals for TC, LDL-C, low HDL-C or elevated TG) classified according to current European Society of Cardiology guidelines.

Results The 4,282 documented patients $(98.6 \%$ Caucasian, $56.4 \%$ male; $86.6 \%$ at high cardiovascular risk) were predominantly treated with simvastatin $(83.9 \%)$, pravastatin $(7.7 \%)$ or atorvastatin $(3.9 \%)$, usually with doses equivalent to simvastatin $20-40 \mathrm{mg}$ daily. Non-statins were used in at most $12 \%$ of patients. No lipid abnormalities were found in $21.0 \%$ of patients, one abnormality in $38.5 \%$, two in $31.9 \%$, and all three in $8.5 \%$. LDL-C goals were not attained in $58.1 \%$, elevated TC was found in $66.6 \%$, low HDL-C in $22.7 \%$, and elevated TG in $47.3 \%$. In the multivariate logistic regression model, non-attainment of LDL-C levels was predicted by hypertension (odds ratio, OR 1.4), current smoking (OR 1.3), sedentary lifestyle (OR 1.3), and female gender (OR 1.3). On the other hand, a reduced risk for missing LDL-C targets was noted in the presence of ischemic heart disease (OR 0.6), diabetes (0.5), higher statin doses, ezetimibe treatment, or specialist care, respectively.

Conclusion A substantial proportion of statin-treated patients not only missed targets for LDL-C, but also did not attain the normal levels for HDL-C and/or TG. There is a large disconnect between high prevalence of HDL and/or TG disorders, with or without elevated LDL-C, and utilization of therapies targeting these lipids. Particularly in high-risk patients, additional efforts should be made to improve their lipid profile.

Keywords Dyslipidemia $\cdot$ High density lipoprotein cholesterol - Statins - Treatment targets - Primary care 


\section{Introduction}

Substantial gains in cardiovascular disease (CVD) prevention have been made in the recent years in the Western industrialised countries [1,2], owing in particular to the earlier identification of patients at high risk and the management of their modifiable risk factors [3]. However, these improvements are now challenged by the impact of the global epidemics of metabolic syndrome, obesity, and type 2 diabetes mellitus $[4,5]$. A high proportion of patients with these conditions have complex lipid abnormalities (dyslipidemia), which are not restricted to elevated low-density cholesterol (LDL-C) or total cholesterol (TC) levels, but often comprise reduced levels of high density lipoprotein cholesterol (HDL-C) and/or elevated triglycerides (TG) [6, 7]. The central role of dyslipidemia as a major contributor to CVD risk was highlighted by the global case-control INTERHEART study, in which the condition was responsible for $54 \%$ of population-attributable risk for myocardial infarction [8]. Further, dyslipidemia is associated with substantial costs for the health care system, for example due to productivity loss [9].

There are stringent dyslipidemia treatment goals for patients with type 2 diabetes or CVD; however, guidelines in high-risk subjects without diabetes or CVD are less strict and are based primarily on LDL-C, with non-HDL concentrations as secondary consideration in some subjects [10]. Extensive evidence from large-scale prospective studies has demonstrated that LDL-C lowering therapies (primarily statins) substantially reduce risk of CVD events in patients at high risk of any type of major vascular event: for every $1 \mathrm{mmol} / \mathrm{L}(39 \mathrm{mg} / \mathrm{dL})$ decrease in LDL-C, the risk of major cardiovascular events is decreased by $21 \%$ [11].

However, even in patients with optimal LDL-C reduction, a high residual risk of atherothrombotic events remains [12]. Further substantial risk reduction is likely to require alternative or supplementary approaches, focusing on HDL-C [13] or TG, too. According to the National Cholesterol Education program (NCEP ATP III), therapeutic intervention targeting low HDL-C and high TG should be initiated in high-risk individuals with these additional lipid abnormalities [14].

Various cross-sectional studies have assessed the prevalence of lipid abnormalities in different populations at risk [15-20]. However, these studies have substantial differences in methodologies and definitions of target groups. Little recent information is available on the prevalence of persistent dyslipidemia in patients treated with statins in a real-life setting, and how their lipid profile is related to patient characteristics. The present study aimed (1) to estimate the prevalence of persistent dyslipidemia (missed goals for LDL-C, TC, low HDL-C, elevated TG) in statintreated patients; (2) to describe the risk factor profiles and lipid-lowering treatment of patients by index disease (coronary artery disease; diabetes mellitus) or elevated risk; and (3) to investigate predictors for non-achievement of various recommended lipid values.

\section{Methods}

Study design

The Dyslipidemia International Survey (DYSIS) is string of epidemiological studies. The German part as reported here was conducted in 748 centres throughout Germany, with the study period being 1 April 2008-30 May 2008. It was purely observational, as only available data were documented, and treatment or assessment of patients was not changed by participation in the study. The Ethics Committee of the Bavarian Physician Chamber in Munich, Germany, approved the protocol. All patients provided written informed consent prior to participation. Data protection was closely observed. A randomly assigned $1 \%$ sample of centres underwent audits for data source verification.

\section{Physicians}

Office-based physicians (GP/family practitioner, internist, cardiologist, endocrinologist) were eligible for participation. The protocol stipulated that the selection of physicians in the study was to be determined to ensure homogeneity and a good representation of the study patient population at the country level. The site selection method was performed at the country level and took the following criteria into account: (a) physician profiles: GPs/family practitioners, internists, cardiologists, endocrinologists; (b) location: administrative region within the country; (c) medical practices: office based, hospital based. From a list of physicians meeting these distribution criteria, the first 748 respondents to the invitation from the sponsor were nominated as investigators. Centres were balanced according to the above criteria and there was no obvious selection bias. Participating physicians documented other characteristics related to their practice (age, gender, practice size, etc.).

They agreed to enrol six consecutive patients fulfilling the inclusion criteria. The specialty of participating physicians was recorded. The physicians received reimbursement of $€ 40$ per patient enrolled.

Patients and schedule

Consecutive outpatients were eligible for participation, if they were at least 45 years old, currently treated with a statin and had had a documented lipid profile (at least 1 
parameter) within the last 6 months. All data requested in the case report form were collected from the patient clinical examination or from the review of the patient chart. Data were recorded at one single visit. In view of the observational character of the study, no safety assessments were part of the protocol.

\section{Documented parameters}

Physicians were requested to document the following parameters at one visit: demographics of the patient (gender, age, race), body weight, height, waist circumference. In terms of lipid parameters, the latest lipid test available within the last 6 months, obtained while the patient had been on statin therapy for at least 3 months was used. All lipid parameters available from that blood test were collected (TC, LDL-C, HDL-C, TG), if available. Cardiovascular risk factors were documented.

Diabetes mellitus was defined as physician diagnosis, serum glucose $\geq 126 \mathrm{mg} / \mathrm{dL}$ ( $\geq 7 \mathrm{mmol} / \mathrm{L}$ ) in latest available lab test or patient currently on antidiabetic or insulin therapy. Elevated fasting plasma glucose was defined as serum glucose $\geq 100 \mathrm{mg} / \mathrm{dL}(\geq 5.55 \mathrm{mmol} / \mathrm{L})$ in latest available lab test. Metabolic syndrome was recorded according to the definition of the International Diabetes Federation [21]. Waist circumference was measured in standing position at the midpoint between the iliac crest and the costal margin in the mid-axillary line (cutoffs $\geq 102 \mathrm{~cm}$ for men, $\geq 88 \mathrm{~cm}$ for women). Hypertension was defined as treatment of previously diagnosed hypertension or blood pressure values $\geq 140 / 90 \mathrm{mmHg}$. Current smoking was recorded if the patient was currently smoking or stopped smoking less than a year ago; past smoking if the patient has stopped smoking over a year ago. First grade family history of premature $\mathrm{CV}$ disease was considered if a first-degree relative (parents, brothers or sisters) suffered from any early manifestation of atherosclerotic cardiovascular disease $(<55$ years in men and $<65$ years in women). Sedentary lifestyle was determined if the patient did not conduct usual physical activity (i.e. a minimum of walking 20-30 min on 3-4 days a week or equivalent). Alcohol consumption was reported as the average number of drinks per week.

Manifestations of cardio- and cerebro-vascular diseases were documented: coronary artery disease (CAD), prior myocardial infarction or coronary revascularization [percutaneous coronary intervention (PCI) and/or coronary artery bypass surgery $(\mathrm{CABG})]$; cerebrovascular disease (prior stroke or transient ischemic attack), peripheral arterial disease (PAD), intermittent claudication or peripheral artery revascularization; symptomatic chronic heart failure according to New York Heart Association Heart Failure Classification Class (NYHA) II-IV.
Medication

The documentation of chronic medication focused on statin therapy. The indication for statin treatment was noted (e.g. hypercholesterolemia), as well as the name and daily dose of the statin taken by the patient at the time of visit as well as at the time of the latest available lipid test. Further, other lipid-modifying therapies (cholesterol absorption inhibitor [CAI], bile acid sequestrants, fibrate, nicotinic acid), at visit and before latest lipid test were documented. Further, antihypertensives, antidiabetics, antiplatelets were recorded.

\section{Treatment goals}

LDL-C treatment goals were $<3 \mathrm{mmol} / \mathrm{L}$ in patients with SCORE risk $<5 \%$, and $<2.5 \mathrm{mmol} / \mathrm{L}$ ) in patients with SCORE risk $\geq 5 \%$, diabetes, and/or CVD. TC treatment goals were $<5 \mathrm{mmol} / \mathrm{L}$ in patients with SCORE risk $<5 \%$, and $<4.5 \mathrm{mmol} / \mathrm{L}$ in patients with SCORE risk $\geq 5 \%$, diabetes mellitus, and/or CVD.

\section{Data entry and analysis}

Physicians could decide to enter the data on paper/pencil case record forms (CRF) or on electronic CRFs via the internet.

Since the objectives of this study were descriptive in nature, no formal hypothesis testing was done. Exploratory prespecified analyses were done for subgroups or regions within each country. No correction for multiplicity was made. Descriptive statistics [mean, standard deviation, range, percentiles, proportions, $95 \%$ confidence intervals (CI), etc.] were calculated for prespecified subgroups defined by lipid abnormalities, age, gender, $\mathrm{CV}$ risk factors and levels, comorbidities, treatment patterns and regions.

Patient characteristics of the entire population and of defined subgroups were described using descriptive statistics [mean with standard deviation (SD), median, interquartile range]. Subgroups were defined pre-hoc: patients with CAD alone; patients with diabetes mellitus alone; patients without diabetes or CAD but with 10-year event risk $\geq 5 \%$ according to the ESC SCORE [22]; patients without diabetes or CAD but with 10 -year event risk $<5 \%$ according to the ESC SCORE. Post hoc analyses were performed to investigate differences in patient characteristics and treatment between these subgroups, using chisquare tests.

A proportional odds model was used to evaluate potential determinants of lipid control. Target levels and other definitions for lipid parameters (LDL-C, TC, HDL-C, TG) were based on the ESC guidelines [23].

Bivariate associations were tested by placing each variable into a separate proportional odds model. For categorical 


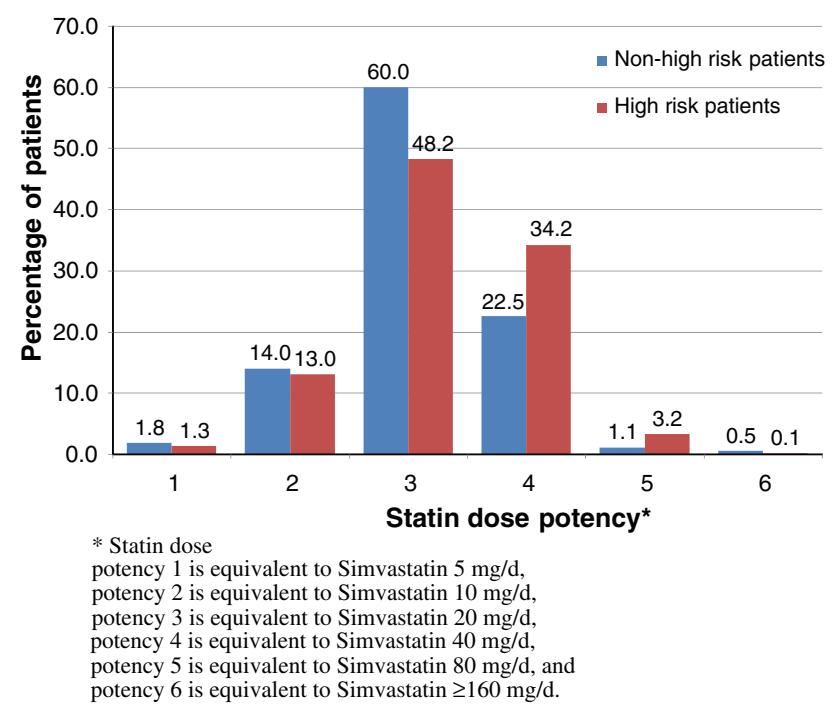

Fig. 1 Statin dose potency

variables, referent variables were created. The proportional odds assumption was not violated for any variables on bivariate analysis at a $p$ value $\leq 0.05$. Models contained the following variables: age, gender, first-degree relative with a history of premature CVD, current smoker, sedentary lifestyle, alcohol consumption $>2$ units/week, BMI $\geq 30 \mathrm{~kg} / \mathrm{m}^{2}$ (obesity), waist circumference $>102 \mathrm{~cm}$ in $\mathrm{men} />88 \mathrm{~cm}$ in women, hypertension, diabetes mellitus, ischemic heart disease, cerebrovascular disease, heart failure, peripheral artery disease, $\mathrm{BP} \geq 140 / 90 \mathrm{mmHg}$ (systolic/diastolic), 20-40 versus $10 \mathrm{mg}$ /day simvastatin equivalent, $\geq 80$ versus $10 \mathrm{mg} /$ day simvastatin equivalent, ezetimibe, physician's specialty. To obtain equivalents for statin potency, all statins were categorised in five potencies (see legend to Fig. 1), using the "rule of 5 in lipid-lowering by statin drugs" by Roberts [24], and the assumption of Knopp [25] that in general, a doubling of the dose above the minimal effective dose decreases serum LDL-C concentrations by an additional 6\%. Backward elimination $(\alpha=0.05)$ was performed. Statistical significance was accepted at the two-sided 0.05 level, and all confidence intervals were computed at the $95 \%$ level. Statistical analyses were performed with SAS version 9.1 (SAS Institute Inc., Cary, NC, USA, 1999).

\section{Results}

Of the participating 748 physicians, $79.9 \%$ were primary care/ family physicians, and $20.1 \%$ were specialists ( $9 \%$ internists, $7 \%$ cardiologists, $4 \%$ endocrinologists/diabetologists).

Patient characteristics and ESC risk level

Patient characteristics are summarized in Table 1. The documented 4,282 patients were almost exclusively
Table 1 Patient characteristics

\begin{tabular}{|c|c|}
\hline & $\begin{array}{l}\text { All patients } \\
(N=4,260)\end{array}$ \\
\hline Age (years), mean $\pm \mathrm{SD}^{\mathrm{a}}$ & $67.1 \pm 9.7$ \\
\hline Caucasian $(\%)$ & 98.6 \\
\hline Gender male $(\%)$ & 56.6 \\
\hline Family history of premature CAD (\%) & 35.1 \\
\hline Current smokers $(\%)$ & 13.6 \\
\hline Hypertension $(\%)$ & 85.7 \\
\hline Systolic BP $(\mathrm{mmHg})$, mean $\pm \mathrm{SD}^{\mathrm{b}}$ & $131.0 \pm 14.5$ \\
\hline Diastolic BP $(\mathrm{mmHg})$, mean $\pm \mathrm{SD}^{\mathrm{b}}$ & $79.6 \pm 8.3$ \\
\hline Waist circumference $(\mathrm{cm})$, mean $\pm \mathrm{SD}^{\mathrm{d}}$ & $102.0 \pm 14.1$ \\
\hline BMI $\left(\mathrm{kg} / \mathrm{m}^{2}\right)$, mean $\pm \mathrm{SD}$ & $28.9 \pm 5.1$ \\
\hline $\mathrm{BMI} \geq 30 \mathrm{~kg} / \mathrm{m}^{2}(\%)$ & 35.4 \\
\hline Metabolic syndrome (IDF definition) $)^{c}$ & 70.8 \\
\hline \multicolumn{2}{|l|}{ ESC risk level } \\
\hline $\begin{array}{l}\text { High risk }(C V D \text {, diabetes and/or } \\
\text { SCORE risk } \geq 5 \%)(\%)^{\mathrm{i}}\end{array}$ & 89.6 \\
\hline $\operatorname{CVD}(\%)$ & 59.1 \\
\hline Diabetes mellitus $(\%)$ & 45.7 \\
\hline SCORE risk $\geq 5 \%(\%)$ without CVD and diabetes ${ }^{\mathrm{i}}$ & 11.4 \\
\hline SCORE risk $<5 \%(\%)$ without CVD and diabetes ${ }^{i}$ & 10.4 \\
\hline $\mathrm{LDL}-\mathrm{C}(\mathrm{mmol} / \mathrm{L})$, mean $\pm \mathrm{SD}^{\mathrm{e}}$ & $2.9 \pm 0.9$ \\
\hline HDL-C $(\mathrm{mmol} / \mathrm{L})$, mean $\pm \mathrm{SD}^{\mathrm{f}}$ & $1.4 \pm 0.4$ \\
\hline $\mathrm{TG}(\mathrm{mmol} / \mathrm{L})$, median, $\mathrm{IQR}^{\mathrm{g}}$ & $1.6(1.2-2.3)$ \\
\hline $\mathrm{TC}(\mathrm{mmol} / \mathrm{L})$, mean $\pm \mathrm{SD}^{\mathrm{h}}$ & $5.1 \pm 1.2$ \\
\hline
\end{tabular}

$C A D$ coronary heart disease, $B P$ blood pressure, $B M I$ body mass index, $C V D$ cardiovascular disease, $D M$ diabetes mellitus, $I D F$ International Diabetes Federation

${ }^{\mathrm{a}}$ Data on 4,228 patients were available, ${ }^{\mathrm{b}}$ data on 4,257 patients were available, ${ }^{\mathrm{c}}$ data on 3,854 patients were available, ${ }^{\mathrm{d}}$ data on 4,239 patients were available, ${ }^{\mathrm{e}}$ data on 3,903 patients were available, ${ }^{\mathrm{f}}$ data on 3,699 patients were available, ${ }^{\mathrm{g}}$ data on 3,735 patients were available, ${ }^{\mathrm{h}}$ data on 4,180 patients were available, ${ }^{\mathrm{i}}$ data on 4,222 patients were available

Caucasian (98.6\%), predominantly elderly (67 \pm 9.7 years), with a slight dominance of males $(56.6 \%)$. As expected, risk factors were prevalent, in particular arterial hypertension $(85.7 \%)$, metabolic syndrome $(70.8 \%)$, diabetes $(45.7 \%)$ and overweight or obesity $(35.4 \%)$. In the descriptive comparison, women were on average older, and more often were assigned the diagnosis metabolic syndrome.

When applying the ESC SCORE $\geq 5 \%$, the diagnoses $\mathrm{CAD}$ or diabetes for categorisation of high risk, the great majority of patients $(89.6 \%$; men more often than women) fell into this group.

Treatment

The great majority of patients were on chronic simvastatin treatment $(83.9 \%)$. Other statins were less frequently 
prescribed: pravastatin in $7.6 \%$, atorvastatin in $3.9 \%$, fluvastatin in $3.0 \%$, and lovastatin in $1.5 \%$.

The majority of patients received statin dose potency in the intermediate range (equivalent to simvastatin 20 or $40 \mathrm{mg} /$ day, Fig. 1).

With regards to other lipid-lowering treatment, ezetimibe was reported in $13.2 \%$ (fixed combination with simvastatin in $7.0 \%$, in free combination with any other statin in $6.2 \%$ ), fibrates in $11.2 \%$, nicotinic acid in $0.7 \%$, and bile acid sequestrants in $0.5 \%$.

Lipid abnormalities

Table 2 summarizes lipid abnormalities, defined by various categories. No lipid abnormalities were found in $21.1 \%$ of statin-treated patients, isolated LDL-C not at goal was found in $25.0 \%$ of patients, LDL-C not at goal + low HDL-C and/or elevated TGs in $33.6 \%$ of patients, LDL-C at goal + low HDL-C and/or elevated TGs were found in $20.3 \%$ of patients. Corresponding numbers in patients with diabetes mellitus and in patients with coronary heart disease without concomitant diabetes mellitus were: no lipid abnormalities in $19.8 / 28.2 \%$ of patients, isolated LDL-C not at goal was found in 17.2/27.8\% of patients, LDL-C not at goal and/or low HDL-C and/or elevated TGs in 36.2/ $26.9 \%$ of patients, LDL-C at goal and/or low HDL-C and/ or elevated TGs were found in $26.9 / 17.0 \%$ of patients (Fig. 2a, b).

Despite treatment, two-thirds of patients (66.2\%) did not attain TC targets, and more than half missed LDL-C targets $(58.6 \%)$. Elevated TG values were documented in about half of the patients $(46.9 \%)$. When regarding risk subgroups, patients with CVD alone had better control rates compared to those with diabetes (without CVD), or ESC $\mathrm{SCORE} \geq 5 \%$.
Predictors for lipid abnormalities

In the multivariate logistic regression models, a number of variables were identified which independently were associated with lipid abnormalities (Table 3 ). With regards to non-achievement of LDL-C levels, presence of elevated blood pressure $(\geq 140 \mathrm{mmHg}$ ) was associated with a $37 \%$ risk increase (compared to individuals without this condition), current smoking with $32 \%$, sedentary lifestyle with $32 \%$, and female gender with a $26 \%$ risk increase. On the other hand, presence of ischemic heart disease decreased risk by $44 \%$, presence of diabetes by $37 \%$, and of obesity by $18 \%$. Further, treatment with higher statin doses or with ezetimibe was associated with good control, as was specialist care.

\section{Discussion}

This large-scale cross-sectional study indicated that despite statin treatment the lipid profile of only every fifth patient reached the target values as recommended by current practice guidelines, while the large majority of high-risk patients still had one or more manifestations of dyslipidemia.

In the recent years, a large number of studies and surveys have investigated lipid goal attainment in the general population or in the primary care setting. However, they had a clear-cut focus on LDL-C (less frequently also on TC), most recently the Kaiser Permante NW (USA) [26], the 4E Registry (Germany) [27], NHANES III (USA) [28], or the Oslo Registry (Norway) [29]. One of the few more comprehensive analyses was based on the US NHANES, where of the total sample $(n=1,111)$ with dyslipidemia, $85 \%$ remained uncontrolled for LDL-C, HDL-C, and or

Table 2 Lipid abnormalities (\%) according to ESC guidelines in all patients

\begin{tabular}{|c|c|c|c|c|c|c|}
\hline & $\begin{array}{l}\text { All patients } \\
(N=4,222)\end{array}$ & $\begin{array}{l}\text { High risk } \\
(N=3,783)^{\mathrm{a}}\end{array}$ & $\begin{array}{l}\text { CVD } \\
(N=2,515)\end{array}$ & $\begin{array}{l}\text { Diabetes without } \\
\text { CVD }(N=785)\end{array}$ & $\begin{array}{l}\text { SCORE risk } \geq 5 \% \\
(N=483)\end{array}$ & $\begin{array}{l}\text { SCORE risk }<5 \% \\
(N=439)\end{array}$ \\
\hline TC not at goal $(\%)^{\mathrm{b}}$ & 66.6 & 65.7 & 59.6 & 71.3 & 88.4 & 73.8 \\
\hline LDL-C not at goal $(\%)^{\mathrm{c}}$ & 58.1 & 58.1 & 52.7 & 61.3 & 83.3 & 58.7 \\
\hline $\begin{array}{l}\text { Low HDL-C }[<1.0(\mathrm{men}) / 1.2 \\
(\text { women) } \mathrm{mmol} / \mathrm{L}](\%)^{\mathrm{d}}\end{array}$ & 22.7 & 23.1 & 24.8 & 24.0 & 12.9 & 18.7 \\
\hline Elevated TG $(>1.7 \mathrm{mmol} / \mathrm{L})(\%)^{\mathrm{e}}$ & 47.3 & 47.5 & 45.9 & 54.3 & 44.6 & 45.2 \\
\hline
\end{tabular}

${ }^{\mathrm{a}}$ High risk $=\mathrm{CVD}$, diabetes, and/or SCORE risk $\geq 5 \%$

b $\mathrm{TC} \geq 5 \mathrm{mmol} / \mathrm{L}$ in patients with SCORE risk $<5 \%$, and TC $\geq 4.5 \mathrm{mmol} / \mathrm{L}$ in patients with SCORE risk $\geq 5 \%$, diabetes, and/or CVD. Data on 4,175 patients were available

${ }^{\mathrm{c}} \mathrm{LDL} \geq 3 \mathrm{mmol} / \mathrm{L}$ in patients with SCORE risk $<5 \%$, and $\mathrm{LDL} \geq 2.5 \mathrm{mmol} / \mathrm{L}$ ) in patients with SCORE risk $\geq 5 \%$, diabetes, and/or CVD. Data 3,887 patients were available

d Data on 3,685 patients were available

e Data on 3,727 patients were available 
Fig. 2 a Lipid profile in all patients. b Lipid profile in diabetic patients and patients with coronary heart disease but no concomitant diabetes mellitus a

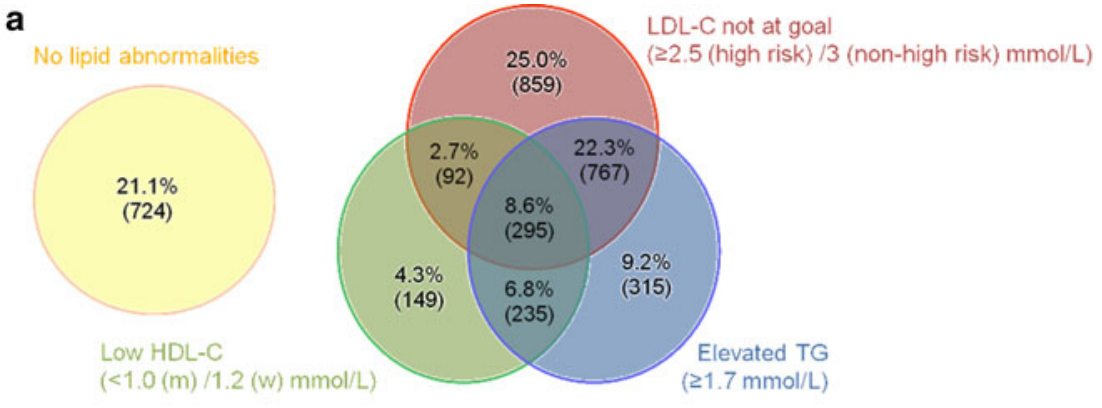

Definition of levels according to ESC guideline on cardiovascular disease prevention. [23]

b

Diabetic patients

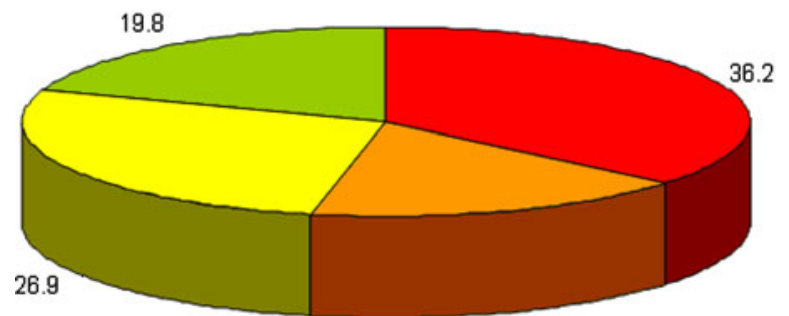

Percentage of patients with

LDL-C not at goal

Low HDL-C and/or high triglycerides $\square$ Normal HDL-C and/or triglycerides

LDL-C at goal

$\square$ LOW HDL-C and/or high triglycerides $\square$ Normal HDL-C and/or triglycerides

17.2

Patients with coronary heart disease but no concomitant diabetes mellitus

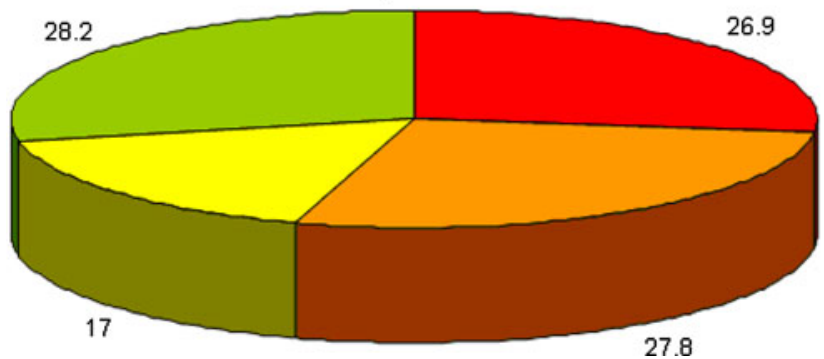

Percentage of patients with

LDL-C not at goal

LOW HDL-C and/or high triglycerides $\square$ Normal HDL-C and/or triglycerides

LDL-C at goal

$\square$ LOW HDL-C and/or high triglycerides $\square$ Normal HDL-C and/or triglycerides

TG; $36 \%$ had more than 2 lipid disorders, while $42 \%$ had HDL-C and/or TG disorders with or without elevated LDL-C [30].

Most of the prior studies on lipid abnormalities focused on LDL-C only based on the recommendations of NCEP ATP III [31, 32]. Our study, however, took a broader perspective, as it also considered HDL-C and TG besides LDL-C, all of which are major contributors to cardiovascular risk.

Our data indicated that overlap of lipid abnormalities was frequent, as in the total cohort $41.2 \%$ of patients had two or three lipid abnormalities at the same time. One out of 12 patients $(8.3 \%)$ presented with abnormalities of all three lipid values, LDL-C, HDL-C and TG, which may pose substantial therapeutic challenges to the physician. Furthermore, additional risk factors and comorbidities such as diabetes or CAD added to the total risk of the patients.

Patients with already manifest cardiovascular disease more often reached the recommended target values for
LDL-C, TC and TG parameters as compared to patients with diabetes but without manifest CVD. Our findings confirm previous reports according to which despite their known risk, patients with diabetes are less often treated according to current guidelines for lipid-lowering therapy $[33,34]$.

The prevalence of low HDL-C and elevated levels of TG was high in DYSIS. A strong reciprocal association between HDL-C plasma concentrations and incidental CAD events was described in different trials [35-37]. Also the PROCAM cohort confirmed this association even after adjustment for other cardiovascular risk factors [38, 39]. Elevated triglycerides were predictors of CAD in univariate analyses in many studies, but failed to predict adverse events in multivariate analyses [38]. This may be due to large inter- as well as intra-individual biological and laboratory variability [40], as well as to the high prevalence of additional abnormalities in HDL-C and LDL-C [10]. Nevertheless, according to the recent consensus conference 


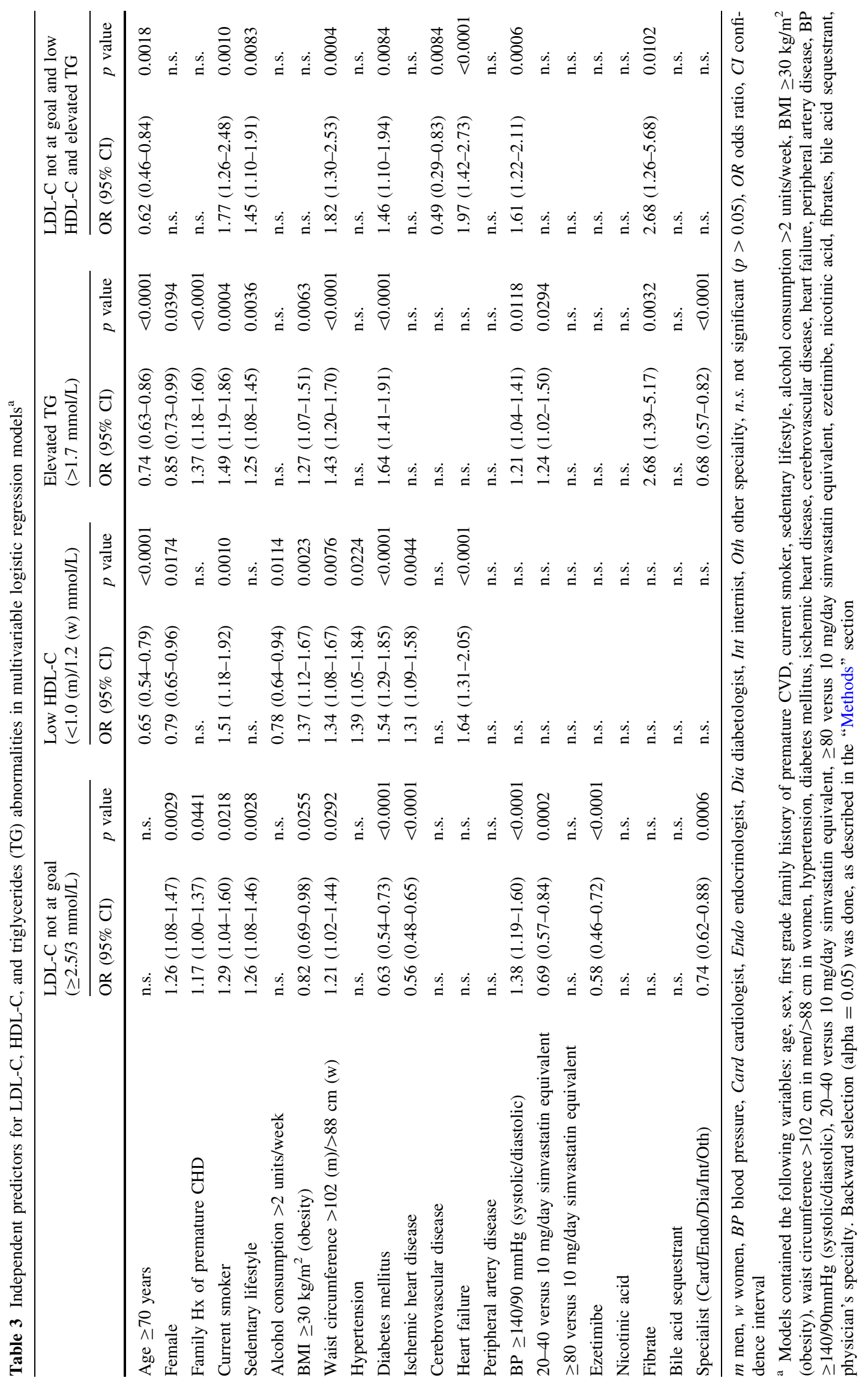


report on lipoprotein management in patients with cardiometabolic risk, treatments inducing HDL-C increase and TG lowering are class II indications [10].

According to the proportional odds model which was used to evaluate potential determinants of lipid control, numerous variables were associated with one or more persistent lipid abnormalities. Risk factors such as smoking, sedentary lifestyle, obesity/increased waist circumference, and hypertension were associated with poor control of at least three of the four assessed lipid abnormalities. Although patients with known diabetes were more likely to reach target LDL-C levels as compared to patients without diabetes and without CAD, still nearly two-thirds of the diabetic patients were not at goal for LDL-C in clinical practice. Additionally, known diabetes also significantly was associated with poor control of HDL-C and TG. These disparate results are not unusual for statin-treated patients who have substantially lowered LDL-C levels, but often abnormal HDL-C or TG values [41, 42]. In DYSIS, specialist care was associated with better LDL-C and TG control, mainly due to the use of higher doses of statins or the add-on of ezetimibe.

Intermediate statin doses equivalent to $20-40 \mathrm{mg} /$ day simvastatin were frequently used in our study. As expected, these doses compared to low doses equivalent to $10 \mathrm{mg} /$ day simvastatin were associated with an increased chance to reach recommended LDL-goals. In the recent $2 \mathrm{~L}$ Registry in 6,711 patients with manifest CAD and/or CAD equivalent the mean simvastatin dose was $25 \mathrm{mg}$ /day at entry and $31 \mathrm{mg} /$ day at discharge [43]. Rates of ezetimibe as combined with statins in our study were $13 \%$ as in the 2L Registry at the baseline visit [43]. Thus, the prescription rates for ezetimibe were increased compared to those reported from statutory health insurance in 2008 , the latest available data (of all daily defined doses for lipid-lowering medications: statins $90.3 \%$, ezetimibe $6.5 \%$, fibrates $2.9 \%$, other $0.3 \%$ ) [44].

We documented a large disconnect between high prevalence of persistent HDL and/or TG disorders independent of the LDL-C levels reached under chronic statin treatment. Similar findings were described by a recent NHANES analysis, in which the rate of therapies targeting these HDL-C or TG was below $<12 \%$ [30].

Four previous studies assessed determinants for lipid control in clinical practice, all focusing on LDL-C target attainment. In an analysis of the Vascular Protection (VP) and the Guidelines Oriented Approach to Lipid Lowering (GOALL) registries, with 8,056 high-risk ambulatory patients, factors significantly associated with treatment success were increasing age (OR 1.5, 95\% CI 1.3-1.7), diabetes mellitus (OR 1.4; 1.3-1.6), CAD (OR 1.3; 1.2$1.5)$, prior PCI or CABG (OR 1.5; 1.3-1.7) and statin therapy (OR 2.3; 2.0-2.5) [45]. Similar findings were documented in the Lipid Treatment Assessment Project (L-TAP) with 4,888 patients [46]. In a retrospective analysis of 8,353 women at high cardiovascular risk in a large managed-care database, predictors of optimal combined lipid level attainment were treatment with lipid-lowering medication (OR 3.6; 95\% CI 3.1-4.2), higher age (>77 years, OR 1.4; 1.1-1.8), diabetes mellitus (OR 1.4; 1.1-1.6), CHD (OR 1.3; 1.03-1.5), and metabolic syndrome (OR 0.4; 0.3-0.5) [47]. Eventually, in the NCEP Evaluation Project Utilizing Novel E-Technology (NEPTUNE II) in 4,885 patients with CHD, diabetes or other CHD risk equivalents, factors associated with goal achievement in the CHD and CHD risk equivalent group were three or more major risk factors (OR 1.3; CI not reported), increasing age (OR 1.7), hypertension (OR 1.2), compliance with diet therapy (OR 1.2), and subspecialties versus primary care (OR 1.8) [48].

The DYSIS study had several strengths and limitations. DYSIS was an observational cross-sectional trial which collected data in a uniform, prospective way in 748 practices across Germany. The collection of observational data in community settings provides more realistic and representative information about the characteristics and management of patients in real clinical practice as compared to randomised clinical trials [49]. However, physicians willing to participate in the survey may be already a selection of physicians with particular interest and knowledge in the field of lipid-lowering therapy. It may be possible that physicians less focused on lipid management are less likely to adhere to stringent guidelines and treatment goals [50]. As noted in studies in other indications, it cannot be excluded that the absence of data from individuals who declined study participation could have affected the findings.

Furthermore, logistic regression analysis can balance only covariates that were assessed and used to construct the model. Other variables, not assessed in the analysis, may be valid predictors for (non-)achievement of lipid goals/normal levels as well. Finally, the present survey was crosssectional and did not describe possible temporal changes in medication. However, the rate of adaptation of treatment was rather low in clinical practice as documented by the TROL Registry [51].

\section{Conclusion}

A majority of statin-treated patients in Germany were not at lipid goals and/or had abnormal levels of HDL-C and triglycerides. DYSIS demonstrates the gap between guideline recommendations and clinical practice and the need for a more intensive and comprehensive lipid management in this high-risk population. The focus in 
secondary prevention should not be just treating hypercholesteremia, but treating to recommended target values to maximally reduce the risk for subsequent adverse cardiovascular events.

Acknowledgments Merck \& Co. Inc. provided financial support to the conduct of the study. The authors thank the participating physicians and their staff. They acknowledge the input of Prof. Dr. David Pittrow, Institute for Clinical Pharmacology, TU Dresden, to the interpretation of the results.

Conflict of interest statement Wenefrieda Smolka and Kurt Bestehorn are employees of a subsidiary of Merck \& Co., Inc. who may potentially own stock and/or hold stock options in the Company. A. K. Gitt has served as a scientific advisor for Merck \& Co., Inc.

Open Access This article is distributed under the terms of the Creative Commons Attribution Noncommercial License which permits any noncommercial use, distribution, and reproduction in any medium, provided the original author(s) and source are credited.

\section{Appendix}

The 12 members of the Scientific Committee are Anselm K. Gitt (Herzzentrum Ludwigshafen, Institut für Herzinfarktforschung Ludwigshafen an der Universität Heidelberg, Germany); Heinz Drexel (Landeskrankenhaus, Feldkirch, Austria); John Feely (Consultant General Physician/Clinical Pharmacologist, Trinity Centre, St. James's Hospital, Dublin, Ireland); Jean Ferrières (Unité de Prévention de l'Athérosclérose, Cardiologie B, Unité 02, CHU Rangueil, Toulouse, France); José-Ramon GonzálezJuanetey (Servicio de Cardiología, Hospital Clínico Universitario, Santiago de Compostela, Spain); Kristian Korsgaard Thomsen (Head of Department of Cardiology, Sydvetjysk Sygehus Esbjerg, Kardiologisk Klinik, Esbjerg, Denmark); Lawrence A. Leiter (St. Michael's Hospital and University of Toronto, Ontario, Canada); Pia Lundman (Danderyds Sjukhus, Hjärt Kliniken, Stockholm, Sweden); Pedro Marques da Silva (Núcleo de Investigação Arterial, Serviço de Medicina, Hospital de Santa Marta, Portugal); Terje Pedersen (Ullevål University Hospital, Oslo, Norway); David Wood (National Heart and Lung Institute, Charing Cross Hospital, Imperial College, London, United Kingdom); John J. P. Kastelein (Academic Medical Center, Amsterdam, The Netherlands).

\section{References}

1. Levi F, Chatenoud L, Bertuccio P, Lucchini F, Negri E, Vecchia CL (2009) Mortality from cardiovascular and cerebrovascular diseases in Europe and other areas of the world: an update. Eur $\mathbf{J}$ Cardiovasc Prev Rehabil 16(3):333-350 (epub ahead of print)
2. Rodriguez T, Malvezzi M, Chatenoud L, Bosetti C, Levi F, Negri E, La Vecchia C (2006) Trends in mortality from coronary heart and cerebrovascular diseases in the Americas: 1970-2000. Heart 92(4):453-460

3. Zeymer U, Parhofer KG, Pittrow D, Binz C, Schwertfeger M, Limbourg T, Rother J (2009) Risk factor profile, management and prognosis of patients with peripheral arterial disease with or without coronary artery disease: results of the prospective German REACH registry cohort. Clin Res Cardiol 98(4):249-256

4. Mainous AG 3rd, Baker R, Koopman RJ, Saxena S, Diaz VA, Everett CJ, Majeed A (2007) Impact of the population at risk of diabetes on projections of diabetes burden in the United States: an epidemic on the way. Diabetologia 50(5):934-940

5. Haffner S, Taegtmeyer H (2003) Epidemic obesity and the metabolic syndrome. Circulation 108(13):1541-1545

6. American Diabetes Association (ADA) (2004) Dyslipidemia management in adults with diabetes. Diabetes Care 27(90001):S68-S71

7. Snow V, Aronson MD, Hornbake ER, Mottur-Pilson C, Weiss KB (2004) Lipid control in the management of type 2 diabetes mellitus: a clinical practice guideline from the American College of Physicians. Ann Intern Med 140(8):644-649

8. Yusuf S, Hawken S, Ounpuu S, Dans T, Avezum A, Lanas F, McQueen M, Budaj A, Pais P, Varigos J, Lisheng L (2004) Effect of potentially modifiable risk factors associated with myocardial infarction in 52 countries (the INTERHEART study): case-control study. Lancet 364(9438):937-952

9. Muller-Nordhorn J, Englert H, Wegscheider K, Berger $\mathrm{H}$, Sonntag F, Voller H, Meyer-Sabellek W, Reinhold T, Windler E, Katus HA, Willich SN (2008) Productivity loss as a major component of disease-related costs in patients with hypercholesterolemia in Germany. Clin Res Cardiol 97(3):152-159

10. Brunzell JD, Davidson M, Furberg CD, Goldberg RB, Howard BV, Stein JH, Witztum JL (2008) Lipoprotein management in patients with cardiometabolic risk: consensus conference report from the American Diabetes Association and the American College of Cardiology Foundation. J Am Coll Cardiol 51(15):1512-1524

11. Baigent C, Keech A, Kearney PM, Blackwell L, Buck G, Pollicino C, Kirby A, Sourjina T, Peto R, Collins R, Simes R (2005) Efficacy and safety of cholesterol-lowering treatment: prospective meta-analysis of data from 90,056 participants in 14 randomised trials of statins. Lancet 366(9493):1267-1278

12. Law MR, Wald NJ, Rudnicka AR (2003) Quantifying effect of statins on low density lipoprotein cholesterol, ischaemic heart disease, and stroke: systematic review and meta-analysis. Brit Med J 326(7404):1423-1430

13. Lee JMS, Choudhury RP (2007) Prospects for atherosclerosis regression through increase in high-density lipoprotein and other emerging therapeutic targets. Heart 93(5):559-564

14. Expert Panel on Detection E, and Treatment of High Blood Cholesterol in Adults (2001) Executive Summary of the Third Report of the National Cholesterol Education Program (NCEP) Expert Panel on Detection, Evaluation, and Treatment of High Blood Cholesterol in Adults (Adult Treatment Panel III). JAMA 285(19):2486-2497

15. Bruckert E, Baccara-Dinet M, McCoy F, Chapman J (2005) High prevalence of low HDL-cholesterol in a pan-European survey of 8545 dyslipidaemic patients. Curr Med Res Opin 21(12):19271934

16. Van Ganse E, Laforest L, Burke T, Phatak H, Souchet T (2007) Mixed dyslipidemia among patients using lipid-lowering therapy in French general practice: an observational study. Clin Ther 29(8):1671-1681

17. Connelly PW, Petrasovits A, Stachenko S, MacLean DR, Little JA, Chockalingam A (1999) Prevalence of high plasma 
triglyceride combined with low HDL-C levels and its association with smoking, hypertension, obesity, diabetes, sedentariness and LDL-C levels in the Canadian population. Canadian Heart Health Surveys Research Group. Can J Cardiol 15(4):428-433

18. Grant RW, Meigs JB (2007) Prevalence and treatment of low HDL cholesterol among primary care patients with type 2 diabetes: an unmet challenge for cardiovascular risk reduction. Diabetes Care 30(3):479-484

19. Primatesta P, Poulter NR (2006) Levels of dyslipidaemia and improvement in its management in England: results from the Health Survey for England 2003. Clin Endocrinol (Oxf) 64(3):292-298

20. Goff DC Jr, Bertoni AG, Kramer H, Bonds D, Blumenthal RS, Tsai MY, Psaty BM (2006) Dyslipidemia prevalence, treatment, and control in the Multi-Ethnic Study of Atherosclerosis (MESA): gender, ethnicity, and coronary artery calcium. Circulation 113(5):647-656

21. Magliano DJ, Shaw JE, Zimmet PZ (2006) How to best define the metabolic syndrome. Ann Med 38(1):34-41

22. Conroy RM, Pyorala K, Fitzgerald AP, Sans S, Menotti A, De Backer G, De Bacquer D, Ducimetiere P, Jousilahti P, Keil U, Njolstad I, Oganov RG, Thomsen T, Tunstall-Pedoe H, Tverdal A, Wedel H, Whincup P, Wilhelmsen L, Graham IM (2003) Estimation of ten-year risk of fatal cardiovascular disease in Europe: the SCORE project. Eur Heart J 24(11):987-1003

23. Graham I, Atar D, Borch-Johnsen K, Boysen G, Burell G, Cifkova R, Dallongeville J, De Backer G, Ebrahim S, Gjelsvik B, Herrmann-Lingen C, Hoes A, Humphries S, Knapton M, Perk J, Priori SG, Pyorala K, Reiner Z, Ruilope L, Sans-Menendez S, Scholte op Reimer W, Weissberg P, Wood D, Yarnell J, Zamorano JL, Walma E, Fitzgerald T, Cooney MT, Dudina A, Vahanian A, Camm J, De Caterina R, Dean V, Dickstein K, Funck-Brentano C, Filippatos G, Hellemans I, Kristensen SD, McGregor K, Sechtem U, Silber S, Tendera M, Widimsky P, Zamorano JL, Hellemans I, Altiner A, Bonora E, Durrington PN, Fagard R, Giampaoli S, Hemingway H, Hakansson J, Kjeldsen SE, Larsen ML, Mancia G, Manolis AJ, Orth-Gomer K, Pedersen T, Rayner M, Ryden L, Sammut M, Schneiderman N, Stalenhoef AF, Tokgozoglu L, Wiklund O, Zampelas A (2007) European guidelines on cardiovascular disease prevention in clinical practice: executive summary. Eur Heart J 28(19):2375-2414

24. Roberts WC (1997) The rule of 5 and the rule of 7 in lipidlowering by statin drugs. Am J Cardiol 80(1):106-107

25. Knopp RH (1999) Drug treatment of lipid disorders. N Engl J Med 341(7):498-511

26. Nichols GA, Nag S, Chan W (2007) Intensity of lipid-lowering therapy and low-density lipoprotein cholesterol goal attainment among the elderly before and after the 2004 National Cholesterol Education Program Adult Treatment Panel III update. Am Heart J 154(3):554-560

27. Assmann G, Benecke H, Neiss A, Cullen P, Schulte H, Bestehorn K (2006) Gap between guidelines and practice: attainment of treatment targets in patients with primary hypercholesterolemia starting statin therapy. Results of the 4E-Registry (Efficacy calculation and measurement of cardiovascular and cerebrovascular events including physicians' experience and evaluation). Eur J Cardiovasc Prev Rehabil 13(5):776-783

28. Persell SD, Lloyd-Jones DM, Baker DW (2006) Implications of changing national cholesterol education program goals for the treatment and control of hypercholesterolemia. J Gen Intern Med 21(2):171-176

29. Ose L, Skjeldestad FE, Bakken IJ, Levorsen A, Alemao EA, Yin DD, Borgstrom F, Jonsson L (2006) Lipid management and cholesterol goal attainment in Norway. Am J Cardiovasc Drugs 6(2):121-128
30. Ghandehari H, Le H, Ambegaonkar B, Sazonov V, Wong N (2008). Abstract 3704: prevalence of lipid disorders and treatment patterns in overall and high risk US adults with dyslipidemia in 2003-2004. Circulation 118 (18_MeetingAbstracts):S_470-c

31. NCEP ATP III guidelines at-a-glance quick desk reference. Available at http://www.nhlbi.nih.gov/guidelines/cholesterol/ atglance.pdf. Accessed on 21 July 2009

32. Grundy SM, Cleeman JI, Merz CN, Brewer HB Jr, Clark LT, Hunninghake DB, Pasternak RC, Smith SC Jr, Stone NJ (2004) Implications of recent clinical trials for the National Cholesterol Education Program Adult Treatment Panel III guidelines. Circulation 110(2):227-239

33. Grant RW, Cagliero E, Dubey AK, Gildesgame C, Chueh HC, Barry MJ, Singer DE, Nathan DM, Meigs JB (2004) Clinical inertia in the management of type 2 diabetes metabolic risk factors. Diabet Med 21(2):150-155

34. Shah BR, Hux JE, Austin PC (2007) Diabetes is not treated as a coronary artery disease risk equivalent. Diabetes Care 30(2):381383

35. Castelli WP, Garrison RJ, Wilson PW, Abbott RD, Kalousdian S, Kannel WB (1986) Incidence of coronary heart disease and lipoprotein cholesterol levels. The Framingham Study. JAMA 256(20):2835-2838

36. Sharrett AR, Ballantyne CM, Coady SA, Heiss G, Sorlie PD, Catellier D, Patsch W (2001) Coronary heart disease prediction from lipoprotein cholesterol levels, triglycerides, lipoprotein(a), apolipoproteins A-I and B, and HDL density subfractions: the Atherosclerosis Risk in Communities (ARIC) Study. Circulation 104(10):1108-1113

37. Stampfer MJ, Sacks FM, Salvini S, Willett WC, Hennekens CH (1991) A prospective study of cholesterol, apolipoproteins, and the risk of myocardial infarction. N Engl J Med 325(6):373-381

38. Assmann G, Schulte H (1992) Relation of high-density lipoprotein cholesterol and triglycerides to incidence of atherosclerotic coronary artery disease (the PROCAM experience). Prospective Cardiovascular Munster study. Am J Cardiol 70(7):733-737

39. Assmann G, Schulte H, von Eckardstein A, Huang Y (1996) High-density lipoprotein cholesterol as a predictor of coronary heart disease risk. The PROCAM experience and pathophysiological implications for reverse cholesterol transport. Atherosclerosis 124(Suppl):S11-S20

40. Wild S, Byrne CD (2008) Time to rethink high-density lipoprotein? Heart 94(6):692-694

41. Ninomiya JK, L'Italien G, Criqui MH, Whyte JL, Gamst A, Chen RS (2004) Association of the metabolic syndrome with history of myocardial infarction and stroke in the Third National Health and Nutrition Examination Survey. Circulation 109(1):42-46

42. Alsheikh-Ali AA, Lin JL, Abourjaily P, Ahearn D, Kuvin JT, Karas RH (2007) Prevalence of low high-density lipoprotein cholesterol in patients with documented coronary heart disease or risk equivalent and controlled low-density lipoprotein cholesterol. Am J Cardiol 100(10):1499-1501

43. Gitt AK, Juenger C, Jannowitz C, Karmann B, Senges J, Bestehorn K (2009) Guideline-oriented ambulatory lipid-lowering therapy of patients at high risk for cardiovascular events by cardiologists in clinical practice: the $2 \mathrm{~L}$ cardio registry. Eur $\mathrm{J}$ Cardiovasc Prev Rehabil 16(4):438-444

44. Häussler B, Höer A, Hempel E, Klein S Arzneimittelatlas (2009) Der Arzneimittelverbrauch in der GKV. Lipidsenkende Mittel. Urban und Vogel, München, pp 147

45. Yan AT, Yan RT, Tan M, Hackam DG, Leblanc KL, Kertland H, Tsang JL, Jaffer S, Kates ML, Leiter LA, Fitchett DH, Langer A, Goodman SG (2006) Contemporary management of dyslipidemia in high-risk patients: targets still not met. Am J Med 119(8):676683 
46. Pearson TA, Laurora I, Chu H, Kafonek S (2000) The lipid treatment assessment project (L-TAP): a multicenter survey to evaluate the percentages of dyslipidemic patients receiving lipidlowering therapy and achieving low-density lipoprotein cholesterol goals. Arch Intern Med 160(4):459-467

47. Mosca L, Merz NB, Blumenthal RS, Cziraky MJ, Fabunmi RP, Sarawate C, Watson KE, Willey VJ, Stanek EJ (2005) Opportunity for intervention to achieve American Heart Association guidelines for optimal lipid levels in high-risk women in a managed care setting. Circulation 111(4):488-493

48. Davidson MH, Maki KC, Pearson TA, Pasternak RC, Deedwania PC, McKenney JM, Fonarow GC, Maron DJ, Ansell BJ, Clark LT, Ballantyne CM (2005) Results of the National Cholesterol
Education (NCEP) Program Evaluation ProjecT Utilizing Novel E-Technology (NEPTUNE) II survey and implications for treatment under the recent NCEP Writing Group recommendations. Am J Cardiol 96(4):556-563

49. Alpert JS (2000) Are data from clinical registries of any value? Eur Heart J 21(17):1399-1401

50. Knight EL, Bohn RL, Wang PS, Glynn RJ, Mogun H, Avorn J (2001) Predictors of uncontrolled hypertension in ambulatory patients. Hypertension 38(4):809-814

51. Bestehorn K, Wegscheider K, Voller H (2008) Contemporary trends in cardiac rehabilitation in Germany: patient characteristics, drug treatment, risk-factor management from 2000 to 2005. Eur J Cardiovasc Prev Rehabil 15(3):312-318 